\title{
Quantification of biogenic volatile organic compounds with a flame ionization detector using the effective carbon number concept
}

\author{
C. L. Faiola, M. H. Erickson, V. L. Fricaud, B. T. Jobson, and T. M. VanReken \\ Laboratory for Atmospheric Research, Department of Civil \& Environmental Engineering, \\ Washington State University, USA
}

Correspondence to: T. M. VanReken (vanreken@wsu.edu)

Received: 7 February 2012 - Published in Atmos. Meas. Tech. Discuss.: 27 March 2012

Revised: 28 June 2012 - Accepted: 16 July 2012 - Published: 10 August 2012

\begin{abstract}
Biogenic volatile organic compounds (BVOCs) are emitted into the atmosphere by plants and include isoprene, monoterpenes, sesquiterpenes, and their oxygenated derivatives. These BVOCs are among the principal factors influencing the oxidative capacity of the atmosphere in forested regions. BVOC emission rates are often measured by collecting samples onto adsorptive cartridges in the field and then transporting these samples to the laboratory for chromatographic analysis. One of the most commonly used detectors in chromatographic analysis is the flame ionization detector (FID). For quantitative analysis with an FID, relative response factors may be estimated using the effective carbon number $(\mathrm{ECN})$ concept. The purpose of this study was to determine the ECN for a variety of terpenoid compounds to enable improved quantification of BVOC measurements. A dynamic dilution system was developed to make quantitative gas standards of VOCs with mixing ratios from 20-55 ppb. For each experiment using this system, one terpene standard was co-injected with an internal reference, noctane, and analyzed via an automated cryofocusing system interfaced to a gas chromatograph flame ionization detector and mass spectrometer (GC/MS/FID). The ECNs of 16 compounds (14 BVOCs) were evaluated with this approach, with each test compound analyzed at least three times. The difference between the actual carbon number and measured ECN ranged from $-24 \%$ to $-2 \%$. The difference between theoretical ECN and measured ECN ranged from $-22 \%$ to $9 \%$. Measured ECN values were within $10 \%$ of theoretical ECN values for most terpenoid compounds.
\end{abstract}

\section{Introduction}

Biogenic volatile organic compounds (BVOCs) are emitted into the atmosphere by vegetation in what is thought to be primarily a plant defense response (Lerdau et al., 1994; Kesselmeier and Staudt, 1999; Engelberth et al., 2004). BVOCs participate in oxidative chemistry in the atmosphere and impact the concentration of air pollutants such as ozone and particulate matter (Atkinson and Arey, 2003). In the United States, emissions of VOCs from plants have been estimated to be approximately 1.5 times greater than the total from anthropogenic sources (Lamb et al., 1987, 1993). This ratio is likely to be even higher in the present day, since vehicle emissions of VOCs have been reduced substantially since the 1980s (Parrish, 2006). More than $50 \%$ of plant VOC emissions belong to the class of compounds that includes terpenes and their oxygenated derivatives (Guenther et al., 2000). A terpene is defined by its molecular structure and chemical formation process. They have molecular structures that include carbon atoms in multiples of five; for example, 5-carbon, 10-carbon, and 15-carbon terpenes are called hemiterpenes, monoterpenes, and sesquiterpenes, respectively. This structural pattern occurs naturally because terpenes are formed biochemically from combinations of the 5-carbon compound isoprene (2-methyl-1,3-butadiene), the only true hemiterpene.

Terpene emission rates depend exponentially on temperature (Guenther et al., 1995), but they are also a function of incoming radiation, nutrient availability, and vegetation type (Guenther, 1997; Lerdau et al., 1997; Demarcke et al., 2010). Measurements of these BVOC emissions are critical to understanding atmospheric chemistry on regional to global scales, but such measurements are very difficult to do 
well and thus their availability is limited. The emission rate measurements that are reported exhibit high intra-species and inter-species variability (Duhl et al., 2008; Ortega et al., 2008). Limited measurements and high variability contribute to uncertainties in biogenic VOC emissions inventories that can be as high as a factor of ten (Guenther et al., 2006; Sakulyanontvittaya et al., 2008). Even less well understood are the changes to BVOC emissions that result from increased herbivory, elevated atmospheric oxidants, drought, and other stressors that are expected to increase in a changing climate (Peñuelas and Staudt, 2010). These factors motivate ongoing studies of biogenic emissions.

As part of the measurement protocol for determining BVOC emission rates, samples are often collected onto adsorptive cartridges in the field and then transported to the laboratory for chromatographic analysis. Quantitative chromatographic analysis normally requires calibrating the detector to each analyte using pure standards. Response factors for target analytes are calculated from standard calibration runs and then subsequently used for quantification in samples. Unfortunately, most environmental samples are a complex mixture of organic compounds, making it nearly impossible to obtain gas-phase analytical standards for each possible analyte. To circumvent this issue, a detector with a predictable response to target analyte compounds may be used, enabling theoretical estimates of response factors without requiring calibrations for each individual analyte.

One of the most commonly used detectors in gas chromatography for this purpose is the flame ionization detector (FID) due to its broad linear range, high sensitivity, and predictable response to organic compounds. An FID works by passing sample gas through a flame generated from pure hydrogen and compressed air. Ions are formed within the flame, and these ions are collected on a biased electrode located adjacent to the flame. A current is produced that is proportional to the number of ions. In the absence of other compounds, hydrogen combustion produces a very low baseline ion signal. When an organic compound enters the flame, C-C bonds are broken via a process called "cracking" and hydrogen atoms are removed via "stripping" reactions. Through these reactions, the individual carbons are converted into the oxomethylium ion $\left(\mathrm{CHO}^{+}\right)$via the following mechanism (Holm, 1999):

$$
\mathrm{CH}+\mathrm{O} \rightarrow \mathrm{CHO}^{*} \rightarrow \mathrm{CHO}^{+}+e^{-} \text {. }
$$

The oxomethylium ion quickly loses a proton to water molecules forming $\mathrm{CO}$ and stable proton-bound water clusters $\left(\left(\mathrm{H}_{2} \mathrm{O}\right)_{n} \mathrm{H}^{+}\right)$. Consequently, the FID is essentially a "carbon counter" and its response to saturated aliphatic molecules is proportional to carbon number. However, FID response decreases as the complexity of the molecular structure increases.

To account for these deviations in FID response, Sternberg et al. (1962) developed the effective carbon number $(\mathrm{ECN})$ concept, which describes the number of carbons in a molecule that the FID "effectively" responds to relative to its aliphatic equivalent. In other words, it is the number of equivalent aliphatic carbons that would produce the same detector response. They proposed that the presence of functional groups decreases the FID response in a predictable way, and that the total ECN of any organic compound can be determined by summing the ECN contribution from each carbon atom present in the molecule. Calculating the ECN of a molecule using the number and type of functional groups present provides a means for estimating relative response factors for quantification. This approach is particularly useful for applications where samples contain a complex mixture of organic compounds, when standards are not realistically accessible, and when accuracy to within a few percent is sufficient - a common scenario for many environmental measurements.

Scanlon and Willis (1985) defined the ECN of a compound as

$$
\mathrm{ECN}_{\mathrm{i}}=\frac{\mathrm{ECN}_{\mathrm{r}}}{F_{(\text {molar })}}=\frac{\mathrm{ECN}_{\mathrm{r}}}{\left(\frac{\mathrm{MW}_{\mathrm{r}} * A_{\mathrm{r}} * m_{\mathrm{i}}}{\mathrm{MW}_{\mathrm{i}} \times A_{\mathrm{i}} \times m_{\mathrm{r}}}\right)}
$$

where $\mathrm{ECN}_{\mathrm{i}}$ and $\mathrm{ECN}_{\mathrm{r}}$ are the effective carbon numbers of the analyte compound and the reference compound, respectively, $F_{\text {(molar) }}$ is the relative molar response factor, $\mathrm{MW}_{\mathrm{i}}$ and $\mathrm{MW}_{\mathrm{r}}$ are the molecular weights, $A_{\mathrm{i}}$ and $A_{\mathrm{r}}$ are the integrated peak areas, and $m_{\mathrm{i}}$ and $m_{\mathrm{r}}$ are the sampled masses of each compound. The relative molar response factor can be calculated if the $\mathrm{ECN}_{\mathrm{i}}$ is known by rearranging the equation above:

$$
F_{\text {(molar) }}=\frac{\mathrm{ECN}_{\mathrm{r}}}{\mathrm{ECN}_{\mathrm{i}}} .
$$

\section{Effect of functional groups on effective carbon number}

FID responses for a number of compounds with various functional groups have been quantified in previous studies. The types of compounds studied, the reference compounds used, and the approach to data presentation all varied in this earlier work, frequently in ways that severely complicate intercomparison. Table 1 summarizes the average ECN contribution from different types of functional group for those studies where ECNs were explicitly presented or could be calculated from the given information. In some cases the previous work contributed to the evolution of the ECN concept but did not explicitly present ECN values; results from these papers are not presented in the table but are included in the following discussion. Table 1 is not intended to be a comprehensive summary of all the results presented in the referenced papers; readers should refer to the original papers for more information. For example, results from halocarbon analyses are not included in Table 1 because they are not the primary focus of this work. 
Table 1. ECN reduction by functional group.

\begin{tabular}{|c|c|c|c|c|c|}
\hline Functional Group & Sternberg et al. (1962) & Tong and Karasek ${ }^{1}$ (1984) & Jorgensen et al. $^{2}$ (1990) & Kállai et al. ${ }^{3}$ (2001) & Kállai and Balla ${ }^{4}$ (2002) \\
\hline Aliphatic & 0 & -0.01 & -0.08 & -0.02 & - \\
\hline Aromatic & 0 & -0.87/aromatic ring (PAHs) & - & $\begin{array}{l}-0.54 \text { (Toluene) } \\
-1.12 \text { (Ethylbenzene) }\end{array}$ & $\begin{array}{l}-0.11 \text { (Benzene) } \\
-0.12 \text { (Toluene) } \\
-0.44 \text { (Ethylbenzene) } \\
-0.78 \text { (Propylbenzene) } \\
-1.50 \text { (Butylbenzene) } \\
-2.08 \text { (Pentylbenzene) }\end{array}$ \\
\hline Olefinic & -0.05 & - & - & - & - \\
\hline Acetylinic & +0.30 & - & - & - & - \\
\hline Carbonyl & -1.0 & - & -0.80 & -0.99 & - \\
\hline Carbonyl + Aromatic & - & -0.48/carbonyl (Oxy-PAHs) & - & - & -0.79 (Acetophenone) \\
\hline Carboxyl & -1.0 & - & - & - & - \\
\hline Nitrile & -0.7 & - & - & - & - \\
\hline Ether & -1.0 & - & -0.75 & - & - \\
\hline Alcohol & $\begin{array}{l}-0.6 \text { (Primary) } \\
-0.75 \text { (Secondary) } \\
-0.25 \text { (Tertiary) }\end{array}$ & - & $\begin{array}{l}-0.42 \text { (Primary) } \\
-0.58 \text { (Secondary) }\end{array}$ & -0.72 (Primary) & - \\
\hline Phenol & - & - & -0.83 & - & -0.22 \\
\hline Furan & - & - & -0.82 & - & - \\
\hline Ester & -0.25 & - & -1.29 & -1.49 & - \\
\hline Amine & $\begin{array}{l}-0.6 \text { (Primary) } \\
-0.75 \text { (Secondary) } \\
-0.25 \text { (Tertiary) }\end{array}$ & - & -0.59 (Primary) & -0.79 (Primary) & - \\
\hline Amine + Aromatic & - & $-0.79 /$ nitro group (Nitro-PAHs) & - & - & -0.26 (Aniline) \\
\hline
\end{tabular}

1 Tong and Karasek (1984) reported absolute response factors. ECN contributions were calculated relative to their results for $\mathrm{C}_{14} \mathrm{H}_{30}$. To isolate the effect of the oxy- or nitro-functional groups, a correction using the average response per aromatic group was applied for each compound. ${ }^{2}$ Jorgensen et al. (1990) used naphthalene as the reference compound, assuming ECN was equal to the number of carbons. ${ }^{3}$ Reference compound was benzene. ${ }^{4}$ Several different aliphatic compounds were used as reference compounds.

Sternberg et al. (1962) proposed the ECN concept, and summarized the individual ECN contributions for 16 different types of functional groups (shown in Table 1). Most of the ECN corrections used to this day originated from this seminal work. Their experimental methods included the analysis of both liquid phase binary standard mixtures and gas-phase standards. They ran 35 standard compounds as binary liquid mixtures that were each injected into the instrument via the liquid injection port; these standards were separated with a GC before introduction into the flame. This method introduced a number of uncertainties. For example, the reference compound had to be changed from run to run to avoid coelution with the analyte. The primary reference compound used was n-heptane, but was replaced with benzene or noctane when necessary. In addition to these liquid analyses, Sternberg et al. (1962) also ran 21 standard compounds as gaseous mixtures in a continuous flow mode where the GC was bypassed and analytes were instead injected directly into the FID. A known amount of standard was added to an 8.21 stainless steel tank, pressurized with hydrogen, and then introduced to the flame through varying restrictors to control and change the introduction flow. This approach allowed them to disentangle response differences that may have been due to chromatographic effects vs. detector effects. This enabled a direct study of the mechanism of the FID response to these compounds. While justifiable with respect to their experimental goals, the dual approach described by Sternberg and co-authors adds further ambiguity to the interpretation of their results. For example, in their paper Sternberg et al. (1962) presented a table summarizing the ECN contribution by functional group type. However, there are apparent inconsistencies between this table and other results presented in the paper. Averaging their results for each compound of a given functional group does not reproduce the values in their summary table, nor can the results be reproduced by combining the gas and liquid experiments nor by just averaging the results from the gas experiments. Presumably the Sternberg team used some combination of their gas-phase and liquidphase results to generate the final ECN contribution summary table, but these details are not included in the paper.

Despite its ambiguities, the work of Sternberg et al. (1962) is very useful for understanding how the presence of functional groups can affect FID response. For example, their results suggested that any carbon that is part of a carbonyl or 
carboxyl group will not contribute to the FID response. This is because the carbon-oxygen bond does not break during the cracking reactions within the flame. Thus, the carbon will maintain connectivity with an oxygen atom after cracking reactions have occurred. This effectively prohibits the generation of the oxomethylium ion from that carbon (via Reaction 1), hence also reducing FID response of the molecule. This same reasoning explains their observation that a carbon associated with an ether functional group was invisible to the FID; one of the carbons adjacent to the ether will be associated with the oxygen atom after cracking and will prevent $\mathrm{CHO}^{+}$genesis.

Sternberg et al. (1962) also found that alcohols are affected by the same processes described above for other oxygencontaining functional groups, but the ultimate effect on FID response is more complex. The magnitude of the reduced FID response from alcohols depends on the likelihood of the carbon-oxygen bond breaking during the cracking process. Secondary alcohols are the most likely to form carbonyl groups and thus exhibited the largest reduction in response $(\triangle \mathrm{ECN}=-0.75)$. Tertiary alcohols, however, cannot form carbonyls because no hydrogen atoms are present on the adjacent carbon. Thus, for tertiary alcohols the primary reaction during cracking will result in the rupture of a carbon-oxygen bond. In this event, the carbon exists in its reduced form post-cracking which allows the formation of the oxomethylium ion. Accordingly, Sternberg et al. (1962) reported a higher response for tertiary alcohols relative to secondary alcohols $(\triangle \mathrm{ECN}=-0.25)$. Primary alcohols produced a response intermediate to tertiary and secondary alcohols $(\triangle \mathrm{ECN}=-0.6)$, in line with the theory outlined above. However, it should be noted that in the Sternberg et al. (1962) work, only one tertiary alcohol compound was analyzed to inform this interpretation of the results, tert-butyl alcohol.

Other studies looking at the effects of molecular structure on FID response were presented at the same symposium where Sternberg et al. (1962) presented their results. Perkins et al. (1962) estimated a theoretical response assuming a decrease in ECN by alcohols and amines of $\sim 0.5$ and by other oxygen-containing functional groups of $\sim 1.0$. Their study included compounds with twelve carbons or less, with a diverse array of functional groups including alkanes, alkenes, aromatics, alcohols, aldehydes, acids, esters, glycols, and amines. Their experimental results agreed well with theoretical values for nearly all compounds. However, they noted that two amino groups had no more effect than one amino group, which was not predicted with the ECN concept. They had no explanation for these anomalous results. Ettre (1962) presented FID responses for paraffins, cycloparaffins, and aromatics for molecules with ten carbons or less. All of these compounds would be expected to have an ECN equal to the actual number of carbons in the molecule. Although the normal paraffins produced the expected results, the cycloparaffins and aromatics had a slightly reduced response that was inconsistent with the ECN correction values presented by Sternberg et al. (1962). A decade later, Clementi et al. (1972) measured ECNs for 19 different compounds representing five general classes of compounds with varying number of carbon atoms. They concluded that the presence of a heteroatom resulted in a decrease in the ECN of the compound by $\sim 1.0$ regardless of the heteroatom type. They also found that tert-butyl groups (i.e. carbons attached to four other carbons and no hydrogens) do not contribute to the ECN at all, though this was not consistent with results from Sternberg et al. (1962) and this finding has not been replicated in more recent studies.

Over time, technological advancements have improved data analysis techniques and allowed some groups to readdress the ECN concept. Jorgensen et al. (1990) quantified ECNs for 56 different compounds of varying carbon number representing 6 different functional group types (Table 1). They replicated many of the compounds from the earlier work of Sternberg et al. (1962), but also filled in some gaps by examining a broader array of substituted compounds. Comparisons between Jorgensen et al. (1990) and Sternberg et al. (1962) reveal some significant differences, most notably for ketones, ethers, and furans. These are probably due to improvements in analytical techniques, but there may have been other experimental differences that contributed to these discrepancies.

The work of Jorgensen et al. (1990) also highlights an additional complication stemming from the choice of reference compounds for deriving ECN values. They used an aromatic compound, naphthalene, as their reference and assumed that aromatic compounds behave similarly to straightchain saturated hydrocarbons in the flame. However, other work has shown that the ECNs of polycyclic aromatic hydrocarbons (PAHs) deviate from their carbon number. Tong and Karasek (1984) measured relative response factors for aliphatic and aromatic compounds, and demonstrated that aromaticity can have a significant impact on ECN contribution for polycyclic aromatic hydrocarbons (Table 1). Kállai and Balla (2002) confirmed the potential impact of aromatic bonds on ECN values, showing that larger aliphatic groups located on an aromatic ring exaggerate the aromatic effect. Kállai and Balla (2002) proposed that this occurs because the residence time in the FID flame is not sufficient to completely decompose larger aliphatic chains connected to aromatic rings. In addition to aromatic compounds, Kállai et al. (2001) and Kállai and Balla (2002) presented ECN values for several homologous series of compounds with a variety of other functional groups represented. Their results agreed well with previous work, but there was some inconsistency in the results between the two papers. Two different types of reference compounds were used for the two papers; this is potentially a contributing factor to the reported discrepancies, particularly for the aromatic compounds. 


\section{Motivation for the current study}

This earlier work evaluating the theoretical ECN values of different carbon bond types has focused almost entirely on compounds with relatively simple linear structures. In practice, these theoretical values are frequently applied to much more complicated organic molecules, including those of biological derivation. Terpenoid compounds are a good example. Even though the atomic structure of terpenes is simple (they are characterized as a hydrocarbon olefin), their geometry can be substantially more complex than those studied previously. They often contain bicyclic structures or highlystrained 3-carbon rings. Such complex structures could potentially impact the way terpenes break down within the FID's hydrogen flame and thus ultimately affect their ECN, as was observed earlier for cyclic paraffins by Ettre (1962).

There are additional reasons for a detailed evaluation of the ECNs for terpene species. The analytes present in a single BVOC cartridge sample can contain numerous terpenoid derivatives with various functional groups, and inconsistencies in the current literature leave questions regarding which values to use to estimate relative response factors. Additionally, Sternberg et al. (1962) and Kállai et al. (2003) have shown that differences in instrumentation and experimental conditions can have impacts on the ECN contributions from heteroatomic groups, resulting in inconsistencies between laboratories. Among others, these factors include the ion collection system, relative flows of the gases, internal oxygen content, and the flame jet diameter and temperature. Consequently, it is still prudent to run a representative standard for each type of molecular structure to be quantified in a sample in order to characterize and calibrate each analytical system. However, terpenoid standards are generally expensive and difficult to obtain, and they are relatively unstable in gas cyclinders. This latter was shown clearly during the Nonmethane Hydrocarbon Intercomparison Experiment (Apel et al., 1999). In that study, two canisters containing over 50 VOCs were sent to 29 institutions for analysis. Of the compounds analyzed, biogenic species were among the most poorly quantified. The average systematic error for alpha-pinene was $-40 \%$, and the mixing ratio had changed by $-15 \%$ within a period corresponding to a few weeks; these and other similar errors were attributed to the instability of biogenic VOC in the stored standards.

Because of all of these issues, there has been no comprehensive study of the ECN values of terpene species before now. However, there has been some previous work related to the topic. In one, Raffa and Steffeck (1988) ran ten liquid monoterpene standards and calculated FID response factors for each terpene relative to n-pentane. They found that each monoterpene had a response factor close to one, i.e. that each had a response nearly equal to its aliphatic equivalent based on their definitions. However, it has been shown that calibrating instruments using liquid injections can contribute to substantial errors in gas-phase VOC analysis, and best practice is that all calibration standards be introduced in as similar a way as possible to the sample introduction method (Apel et al., 1999). Additionally. Raffa and Steffeck (1988) had difficulty quantifying myrcene and they neglected to run any terpenoid derivatives that are also likely to be present in any environmental samples. Another relevant study was published by Komenda et al. (2001). They designed a diffusion cell to produce gas-phase standards of various BVOCs including terpenes, oxygenated terpenoids, and aldehydes. They used the ECN concept in their analysis to correct their relative response factors, but did not report the specific ECN contributions they used for their corrections. The omission is problematic since the interpretation of their results depends critically on the ECN values used. For example, the Komenda team found that the ECN correction required for monoterpene analysis was small enough to be ignored within the uncertainty of their analytical system. However, they also stressed that the ECN correction applied to oxygenated compounds significantly improved results; without the correction, oxygenated compound responses differed by more than $30 \%$ from the mean, but with the ECN correction applied the response differed by only $7 \%$. Neglecting the ECN correction in this circumstance would result in severe under-predictions of the emission rates of these compounds. Komenda et al. (2001) also noted specific problems in quantifying ocimene and trans-caryophyllene, suggesting there may be issues in quantifying these particular compounds with their analytical system. They suggested that comparing response factors of different VOCs is a useful quality control check on any analytical system, particularly since most BVOC analyses include quantification of compounds that have not been individually calibrated.

The objective of this study was to calculate the ECNs of a variety of representative BVOC compounds with an automated cryotrapping and analytical system used for BVOC analysis. To accomplish this, a dynamic dilution system was built in order to generate gas-phase standards with a known mixing ratio from liquid analytical standards. The reproducibility and accuracy of the dynamic dilution system was characterized with a proton transfer reaction mass spectrometer (PTR-MS). Gas-phase standards generated from this system were used to calculate ECNs of terpenoid compounds. The reproducibility and reasonableness of the measured ECN values were used as a quality control to improve the BVOC analytical system for future analyses.

\section{Methods}

\subsection{Generation of gas standards}

The dynamic dilution system was used to make stable, reproducible, quantitative gas standards of VOCs with mixing ratios between 20 and 55 ppbv. The actual dynamic range of the system is much larger, from approximately $2-1000 \mathrm{ppbv}$ for 


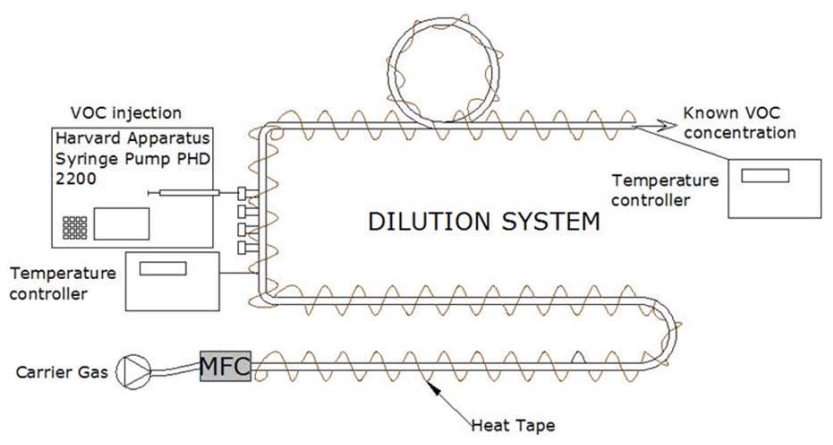

Fig. 1. Schematic of the dynamic dilution system built for generating gas terpenoid standards.

most organic compounds of intermediate volatility, assuming a dilution flow capability from 5-20 SLPM. A schematic of the dilution system is shown in Fig. 1. The system consists of three main components: the heated carrier gas flow, the VOC injection system, and the mixing loop. The main flow path of the dilution system was assembled from 0.25 inch $(6.4 \mathrm{~mm})$ outside diameter (OD) stainless steel (SS) tube and Swagelok fittings with graphite ferrules. The SS tube was curved in two places, creating a "U" shape, and a mixing loop was installed near the outlet to ensure that the output was homogeneously mixed. The carrier gas was dry $\mathrm{N}_{2}$ blow-off from a liquid nitrogen dewar and was introduced into the dilution system via a mass flow controller (MFC, Alicat Scientific, model MC 20SLPM-D/5V). The carrier flow could be varied to obtain the desired outlet VOC concentration. VOC mixing ratios were calculated from the infusion rate and the dilution flow using the density and molecular weight of the liquid standard being injected. Hydrocarbons were introduced in the dilution system with precision microliter syringes (Hamilton, model, $7000.5 \mathrm{KH}$ ) that were filled with a liquid standard purchased from Sigma-Aldrich. Syringe needles were inserted through a septum attached to a SS Swagelok tee on the dilution system. The VOC injection rate was controlled with a syringe pump (Harvard Apparatus, model PHD 2200), which allowed highly precise low flow rates on the order of a fraction of a $\mu \mathrm{h}^{-1}$. Tubing between the dynamic dilution system and the instrument sampling system were kept as short as possible and all lines were composed of PFA tubing to minimize adsorption of the analyte onto the inner surface of the tubing.

The system was held at a temperature that was chosen based on the boiling point of the VOC to be measured. If temperatures were too high, evaporation of the compound could occur within the syringe needle, resulting in the production of highly variable output concentrations. On the other hand, if temperatures were too low, liquid droplets could fall into the tubing line and generate inconsistent bursts of heightened concentrations. Appropriate temperatures for a small representative list of compounds are given in Table 2. Each of these operating temperatures was experimentally validated
Table 2. Operating temperatures of the dilution system for the compounds tested.

\begin{tabular}{lrr}
\hline Compound & Temperature & Boiling point \\
\hline Toluene & $45^{\circ} \mathrm{C}-60^{\circ} \mathrm{C}$ & $110.6^{\circ} \mathrm{C}$ \\
1,2,4-trimethylbenzene & $45^{\circ} \mathrm{C}$ & $169^{\circ} \mathrm{C}-171^{\circ} \mathrm{C}$ \\
$\alpha$-Pinene & $45^{\circ} \mathrm{C}$ & $155^{\circ} \mathrm{C}$ \\
Butanol & $35^{\circ} \mathrm{C}$ & $118^{\circ} \mathrm{C}$ \\
Beta-caryophyllene & $55^{\circ} \mathrm{C}-65^{\circ} \mathrm{C}$ & $262^{\circ} \mathrm{C}-264^{\circ} \mathrm{C}$ \\
\hline
\end{tabular}

using a PTR-MS to assess VOC output stability. To maintain the desired temperature of the system, the dilution flow was heated by wrapping heat tape (Omega, model HTC060) around the tube, then wrapping the heat tape with aluminum foil. The temperature of the dilution flow was monitored using a thermocouple (Omega, Type K) that was held inside the fluid stream via a Swagelok tee, nut, and septum. It was connected to a temperature controller (Omega, model $\mathrm{CN} 7500)$ to maintain the desired temperature upstream of VOC injection.

The dynamic dilution system was characterized with a PTR-MS to ensure that consistent, quantitative mixing ratios of the VOCs were being produced. Details on the calibration and performance of the PTR-MS used in this study have been described by Jobson and McCoskey (2010). The PTRMS response was calibrated by diluting a compressed gas VOC standard (Scott-Marrin) containing alpha-pinene and 12 other VOCs in dry nitrogen to 19.8 ppbv. Results from the production of standard gas-phase mixing ratios of toluene, 1 , 2, 4-trimethylbenzene, and alpha-pinene are shown in Fig. 2. The $\mathrm{x}$-axis corresponds to the number of instrument measurement cycles, with each cycle lasting approximately six seconds. The y-axis corresponds to the PTR-MS signal, counts per second (cps), normalized by the hydronium $\left(\mathrm{H}_{3} \mathrm{O}^{+}\right)$ion concentration to account for changes in instrument response due to variations in the reagent ion (de Gouw and Warneke, 2007). It is important to note that the PTR-MS analyte concentration results (and thus its sensitivity) were not used in our analysis. Only the normalized counts per second from the instrument were used to determine the stability and variability of the dynamic dilution system. After an initial equilibration period, the PTR-MS signal variability at the dynamic dilution system outlet was less than $10 \%$ for all three organic compounds. The alpha-pinene data illustrates that the system took approximately $30 \mathrm{~min}$ to equilibrate and then maintained a relatively stable output for the next $2.4 \mathrm{~h}$. The relative standard deviation (RSD) of the alpha-pinene output after the 30 min equilibration period was $8.4 \%$. The output for the other two organic compounds was also stable, with RSDs of $3.8 \%$ and $4.8 \%$ for toluene and 1,2,4-trimethylbenzene, respectively. Based on the results from the PTR-MS, the dilution system was allowed to equilibrate for a minimum of $30 \mathrm{~min}$ prior to sampling. 

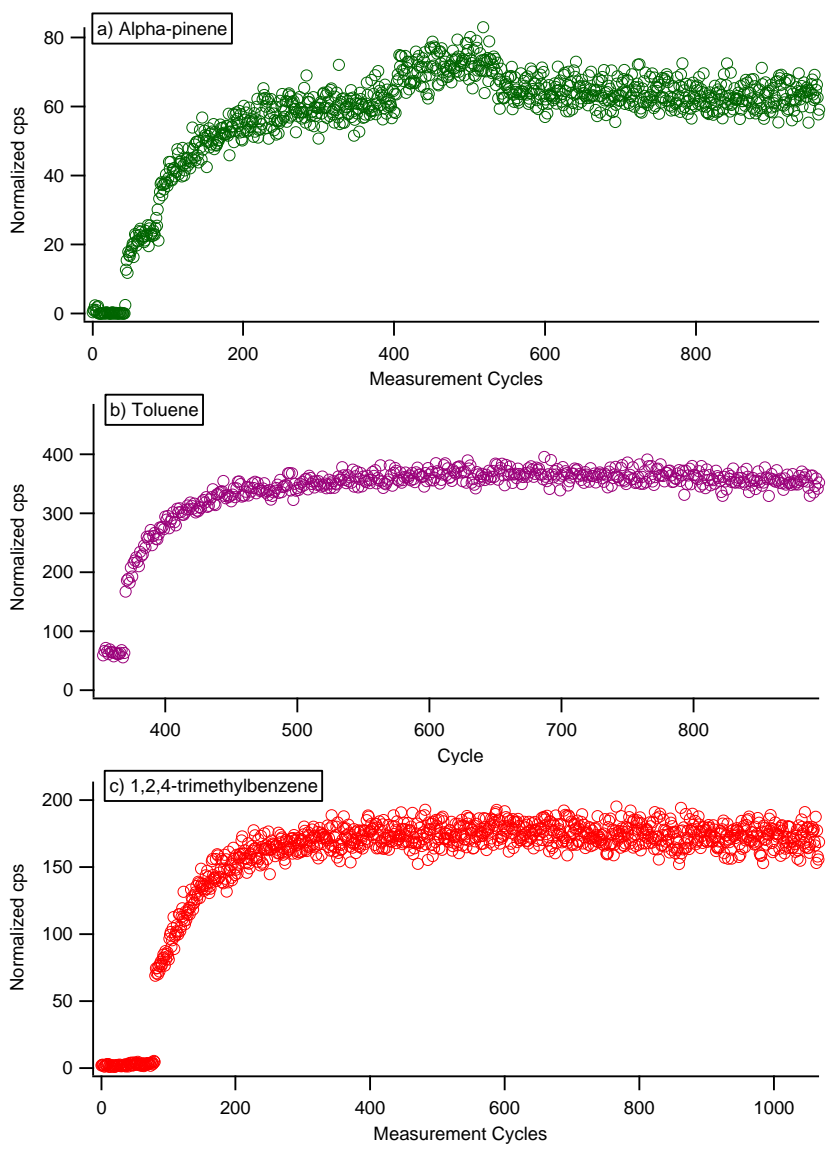

Fig. 2. Three of the gas-phase organic compounds generated with the dynamic dilution system. All mixing ratios at the outlet remained stable, (a) alpha-pinene for 2.4 hours $(\mathrm{RSD}=8.38 \%)$ (b) toluene for $51.8 \mathrm{~min}(\mathrm{RSD}=3.81 \%)$ (c) 1,2,4-trimethylbenzene for $1.56 \mathrm{~h}(\mathrm{RSD}=4.75 \%)$.

\subsection{Instrumentation and calculations}

Gas-phase terpenoid standards produced with the dynamic dilution system were analyzed with an Agilent 6890 Gas Chromatograph with Flame Ionization Detector (GC/FID) (DB-5MS column: $30 \mathrm{~m} \times 0.320 \mathrm{~mm}$ with $1.0 \mu \mathrm{m}$ thickness), interfaced to an Agilent 5973 Mass Spectrometer (MS). Column outflow was split with a column splitter to both the FID and MS detectors (SGE Analytical Science Product No. 123710). A laboratory-built automated cryotrapping system was used to collect samples from the outlet of the dynamic dilution system before injection into the GC (Fig. 3). A twoposition, six-port Valco valve (VICI Product No. DC6UWE) was used to transition between two configurations: sample "load" and sample "inject". In the "load" configuration, the valve was open and flow was connected from the sampling line through the cryotrapping loop and into the reference volume. Sample flow was controlled manually using an adjustable flow restrictor. During cryotrapping, the sample collection loop, made from inert stainless steel tubing (Restek
Sulfinert Product No. 22505), was immersed in liquid nitrogen; the level of liquid nitrogen in the cryotrap dewar was controlled by opening a valve to allow helium gas to bubble into the dewar. After cryotrapping for ten minutes, the system was switched to the "inject" configuration (shown in the inset in Fig. 3). In this configuration, liquid nitrogen levels in the cryotrap dewar were reduced by closing the helium valve, the cryotrapping loop was resistively heated to $\sim 100$ $150^{\circ} \mathrm{C}$, and the Valco valve position was changed so that flow was connected from the GC carrier gas through the loop and into the GC. The total amount of air sampled was calculated using a reference volume system. The reference volume was located downstream of the cryotrapping loop; its volume was known to high precision and its pressure and temperature were continuously monitored, allowing the total moles of air sampled to be readily calculated. With known mixing ratios of standard gas from the dilution system, the moles of analyte that were collected could also be determined. Using these relationships, Eq. (1) could be converted to an equivalent, more appropriate form for this system:

$\mathrm{ECN}_{\mathrm{i}}=\frac{\mathrm{ECN}_{\mathrm{r}}}{\left(\frac{A_{\mathrm{r}} * \chi_{\mathrm{i}} *\left(\frac{P_{\mathrm{i}} V}{R T_{\mathrm{i}}}\right)}{A_{\mathrm{i}} * \chi_{\mathrm{r}} *\left(\frac{P_{\mathrm{V}} V}{R T_{\mathrm{r}}}\right)}\right)}$.

Here, $\chi_{\mathrm{i}}$ and $\chi_{\mathrm{r}}$ are the mixing ratio of the analyte compound and reference, respectively, $P_{\mathrm{i}}$ and $P_{\mathrm{r}}$ are the reference volume pressures, $V$ is the constant volume of the reference volume container, $T_{\mathrm{i}}$ and $T_{\mathrm{r}}$ are the reference volume temperatures, and $R$ is the gas constant. When using an internal standard, the reference volume pressure and temperature will be the same for both the analyte compound and reference compound. The equation thus simplifies to:

$\mathrm{ECN}_{\mathrm{i}}=\frac{\mathrm{ECN}_{\mathrm{r}}}{\left(\frac{A_{\mathrm{r}} * \chi_{\mathrm{i}}}{A_{\mathrm{i}} * \chi_{\mathrm{r}}}\right)}$.

To calculate ECN values, an n-alkane should be chosen as the reference so that the $\mathrm{ECN}_{\mathrm{r}}$ may be defined as the number of carbons in the n-alkane. However, if an n-alkane is unavailable for use as a reference, another material may be used instead so long as its ECN value has been determined relative to an n-alkane.

Measured ECN values were compared to carbon number $\left(N_{\mathrm{C}}\right)$ and the theoretical $\mathrm{ECN}$ values $\left(\mathrm{ECN}_{t}\right)$ by calculating a relative difference, $\triangle \mathrm{ECN}$ :

$\Delta \mathrm{ECN}=\frac{\mathrm{ECN}_{\mathrm{i}}-\mathrm{ECN}_{t}}{\mathrm{ECN}_{t}}$ or $\Delta \mathrm{ECN}=\frac{\mathrm{ECN}_{\mathrm{i}}-N_{\mathrm{C}}}{N_{\mathrm{C}}}$.

The theoretical ECN values of the terpenoid standards were based on results from Sternberg et al. (1962) for all functional groups except aromatic groups. To estimate the contribution from aromatic groups, toluene results from Kallai et al. (2001) were used. A table of the ECN contributions of various functional groups used in this study to calculate theoretical values is presented in Table 3 . 


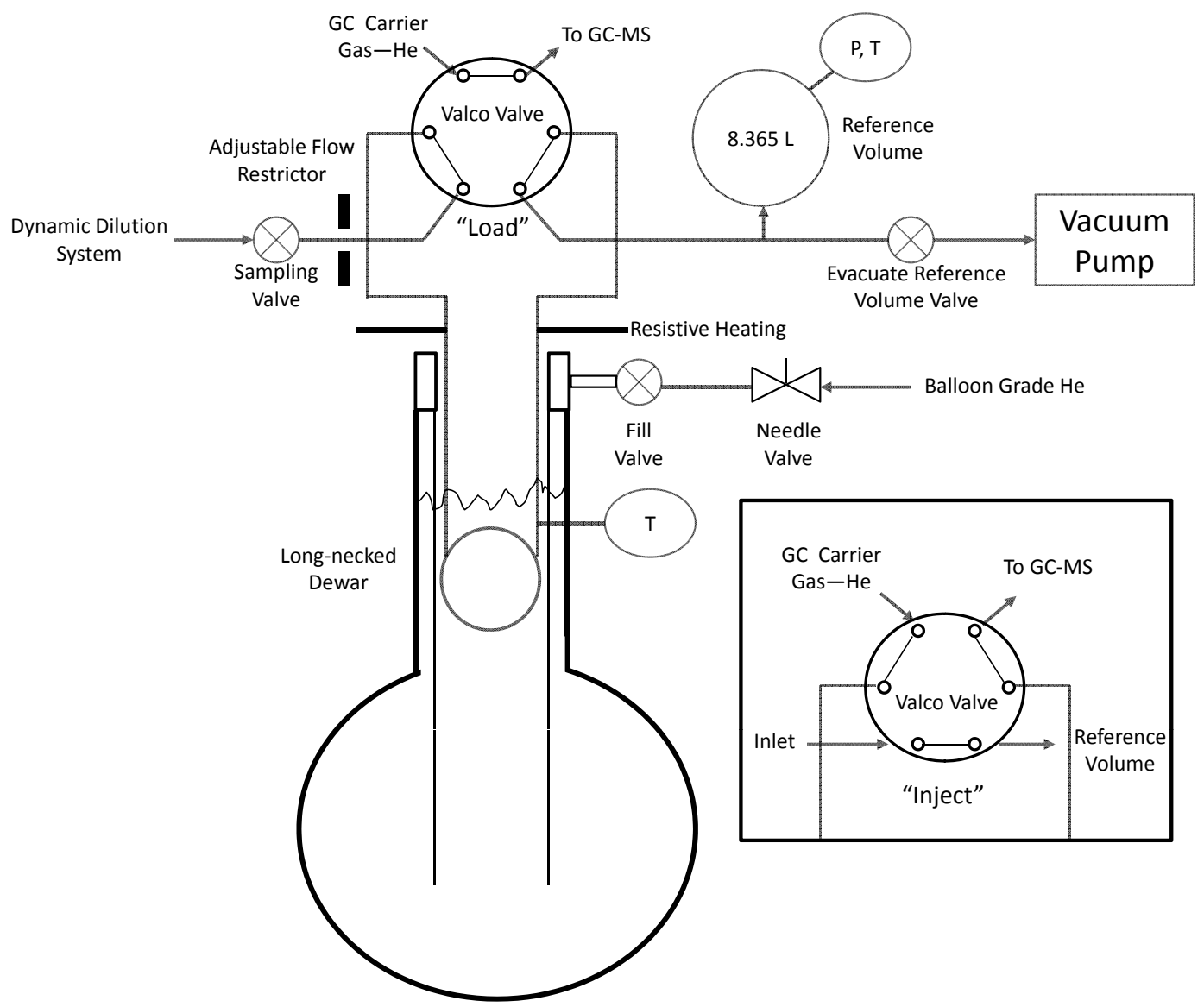

Fig. 3. Schematic of the automated sampling/cryotrapping system used to analyze terpenoid standards generated with the dynamic dilution system. The figure is shown in the "load" sample position. The inset illustrates the valve connections while in the "inject" sample position.

Table 3. ECN corrections applied for analysis in this experiment.

\begin{tabular}{lr}
\hline Functional Group & ECN Reduction \\
\hline Olefinic C & -0.05 \\
Carbonyl & -1.00 \\
Tertiary Alcohol & -0.25 \\
Ether & -1.00 \\
Aromatic & -0.54 \\
\hline
\end{tabular}

\subsection{Experimental approach}

All terpene gas-phase mixtures were produced from liquid standards purchased from Sigma-Aldrich, with purities of $95 \%$ or higher. The only exception was terpinolene, which was obtained at $\geq 90 \%$ purity. The presence of compound impurities were visible in the chromatographs in a few cases. All reported mixing ratios have been corrected for such impurities (if present) by the following procedure. First, the compound impurities in the chromatograph were chemically identified using the mass spectra. Next, the theoretical ECN values of those compounds were applied to the FID response to estimate the concentration of each impurity. We found that the total integrated peak area for all impurities was always less than $10 \%$ of the integrated area for the target analyte peak. Since the compound impurities would be expected to co-vary with the target analyte, this suggests that the compound impurities would contribute no more than one-tenth of the overall uncertainty in the final analysis. All standards were run a minimum of three times relative to an internal standard, n-octane. The ECN of the straight-chain hydrocarbon standard, n-octane, was taken to be exactly eight by definition (i.e. equal to the number of carbon atoms in the molecule).

\section{Results and discussion}

Sixteen separate compounds were run through the automated sampling/cryotrapping system using the dynamic dilution system to generate gas-phase standards with known mixing ratios. Thirteen of these were terpenes or terpenoid derivatives. One, o-cymene, is a biogenic emission that has been reported previously (Ortega et al., 2008). Two were calibrated to n-octane for internal use as laboratory 
Table 4. Summary of study results.

\begin{tabular}{|c|c|c|c|c|c|c|c|}
\hline Compound & $\begin{array}{l}\text { Molecular } \\
\text { Structure }\end{array}$ & Carbon \# & $\begin{array}{r}\text { Theoretical } \\
\text { ECN }\end{array}$ & $\begin{array}{r}\text { Measured } \\
\text { ECN }\end{array}$ & RSD & $\begin{array}{r}\triangle \mathrm{ECN} \text { from } \\
\text { Carbon } \#^{1}\end{array}$ & $\begin{array}{l}\triangle E C N \text { from } \\
\text { Theoretical }^{1}\end{array}$ \\
\hline & & & & & & & \\
\hline 2-Methyl-3-buten-2-ol (MBO) & & 5 & 4.65 & 4.58 & 0.093 & -0.08 & -0.02 \\
\hline 3-Carene & & 10 & 9.9 & 9.40 & 0.048 & -0.06 & -0.05 \\
\hline Terpinolene & & 10 & 9.8 & 9.46 & 0.054 & -0.05 & -0.03 \\
\hline Limonene & & 10 & 9.8 & 9.50 & 0.069 & -0.05 & -0.03 \\
\hline Alpha-pinene & & 10 & 9.9 & 9.76 & 0.042 & -0.02 & -0.01 \\
\hline Beta-pinene & & 10 & 9.9 & 9.50 & 0.074 & -0.05 & -0.04 \\
\hline Alpha-terpinene & & 10 & 9.8 & 9.65 & 0.069 & -0.03 & -0.02 \\
\hline Myrcene & & 10 & 9.7 & 7.58 & 0.066 & -0.24 & -0.22 \\
\hline O-cymene & & 10 & 9.46 & 9.42 & 0.028 & -0.06 & -0.005 \\
\hline Alpha-thujone & & 10 & 9.00 & 8.92 & 0.053 & -0.11 & -0.01 \\
\hline Linalool & & 10 & 9.55 & 8.20 & 0.023 & -0.18 & -0.14 \\
\hline Linalool oxide & & 10 & 8.65 & 8.92 & 0.002 & -0.11 & 0.03 \\
\hline Aromadendrene & & 15 & 14.9 & 13.74 & 0.154 & -0.08 & -0.08 \\
\hline Beta-caryophyllene & & 15 & 14.8 & 13.35 & 0.065 & -0.11 & -0.10 \\
\hline 2,2-Dimethylbutane & & 6 & 6 & 5.86 & 0.006 & -0.02 & -0.02 \\
\hline 1,2,4-Trimethylbenzene & & 9 & 8.88 & 9.22 & 0.041 & 0.02 & 0.04 \\
\hline
\end{tabular}

1 Definitions of $\triangle \mathrm{ECN}$ are given in Eq. (5). 


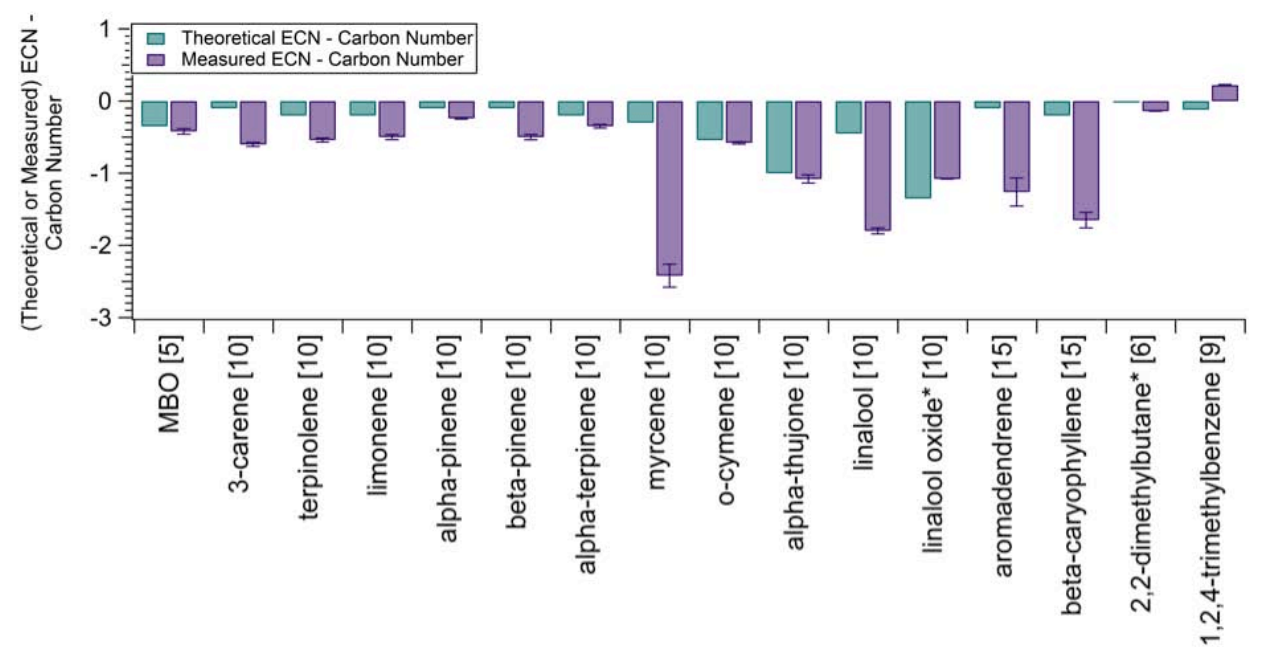

Fig. 4. A comparison of the carbon number difference for theoretical vs. measured ECN values for all the gas standards generated with the dynamic dilution system. The carbon number is shown in brackets after the compound name along the bottom axis. Error bars represent one standard deviation from the average value. *Standard deviations for linalool oxide and 2,2-dimethylbutane were 0.002 and 0.0008 , respectively, and are too small to be seen on this scale.

standards: 2,2-dimethylbutane and 1,2,4-trimethylbenzene. 2,2-dimethylbutane is a highly stable compound that is used as a NIST-certified external FID standard. 1,2,4trimethylbenzene is a standard that does not present as an artifact in cartridge analyses. The results for all sixteen compounds are presented in Table 4. Molecular structures, carbon number, theoretical ECNs, measured ECNs, relative standard deviation (RSD) of the results, and the $\triangle \mathrm{ECN}$ for both carbon number and theoretical ECN are presented.

Of the compounds studied here, two have values reported in the literature for direct comparison. Jorgensen (1990) calculated the ECN of 1,2,4-trimethylbenzene to be 9.09; this study found the ECN of the same compound to be 9.22 $( \pm 4.1 \%)$. This is good agreement, though the strength of the comparison is somewhat compromised by Jorgensen's choice of naphthalene as a reference standard (cf. the discussion in Sect. 2). Sternberg et al. (1962) ran 2,2-dimethylbutane (6-carbon compound) and measured the ECN of this compound to be 6.13. Results from Clementi (1972) suggest that the ECN of this same compound should be 5 since it contains a quaternary carbon that they claim cannot contribute to the FID response. Results from this study measured the ECN of 2,2-dimethylbutane to be $5.86( \pm 0.6 \%)$. These results suggest there is some rearrangement of the molecule occurring that allows the FID to respond to the quaternary carbon most of the time, and the corresponding reduction in ECN of a molecule with a quaternary carbon is approximately -0.25 . Recall that this value is consistent with the response of other carbons lacking adjacent hydrogen atoms that were discussed previously: carbons associated with tertiary alcohols. The similarity between both the structure and ECN value for these two groups lends some credibility to this result for quaternary carbons since the FID mechanism for both classes of compounds may be quite similar. However, the ECN of tertiary alcohols is based on results from a single compound (see discussion in Sect. 2). Ultimately, the response of quaternary carbons in the FID appears to be unresolved due to inconsistencies between studies.

The ECN values of terpenoid compounds were the major focus for this study. As seen in Table 4 and Fig. 4, all monoterpenes sampled except for myrcene exhibited $\triangle \mathrm{ECN}$ of less than $10 \%$ relative to their carbon number. Consequently, the theoretical ECN correction for monoterpenes is insignificant for this system. However, for the oxygenated terpenoids the $\triangle \mathrm{ECN}$ relative to carbon number was frequently greater than $10 \%$, suggesting that neglecting this correction would produce erroneously low results for these compounds. This result is in agreement with earlier findings of Komenda et al. (2001). The measured ECN values for the sesquiterpenes were within $11 \%$ or less of the theoretical ECN. However, the sesquiterpenes deviated from the theoretical values more than most of the monoterpenes; while most monoterpenes deviated from carbon number by $5 \%$ or less, the two sesquiterpenes run here deviated from carbon number by $8 \%$ and $11 \%$ for aromadendrene and betacaryophyllene, respectively. This is approaching or, for betacaryophyllene, slightly exceeding the uncertainty of this analytical method. Unfortunately, only two sesquiterpene compounds were available for analysis, making it difficult to draw general conclusions regarding the entire class. Moreover, one of the two sesquiterpenes tested, aromadendrene, was only run in duplicate rather than triplicate and exhibited a much higher RSD than any of the other compounds.

Generally, sesquiterpenes are known to be much more difficult to analyze than monoterpenes due to their high 
reactivity and low volatility. Similar difficulties were experienced in this study. Initial attempts to sample sesquiterpenes yielded much less signal than was expected; in many cases no analyte peak was observed in either the FID or the MS. We considered several possibilities for what might cause the severe reduction in sesquiterpene transmission through our system, including increased wall adsorption. We discounted wall adsorption as the cause after checking the temperature along the entire heated sampling line and increasing equilibration time for the dynamic dilution system; the sesquiterpenes were still absent from the detector signals. We next tried increasing the cryotrapping temperature from -196 to $-130^{\circ} \mathrm{C}$ and decreasing the temperature gradient along the loop; this was done by manually adjusting the depth of immersion of the loop in a small liquid nitrogen dewar and by approximately doubling the length of the loop. When testing the system with these modifications, the full sesquiterpene peak was finally observed. This result suggests that homogeneous nucleation of sesquiterpenes was likely occurring within the sampling loop during the initial runs, and that consequently these less volatile, bulkier compounds were not adsorbing onto the cryotrapping loop, but were rather being carried with the sampling flow into the reference volume. Adjustments were made to the system to ensure this would not happen during future analysis.

For reasons that remain unclear, myrcene could not be quantified well with this system. Raffa and Steffeck (1988) had similar difficulties in their study. The molecular structure of myrcene is similar to that of the ocimenes (they are both acyclic monoterpenes), which Komenda et al. (2001) also had difficulty quantifying. This suggests that there may be some real issue quantifying these types of monoterpenes with the systems described both here and in Komenda et al. (2001). Fahlbusch et al. (2003) proposed that these acyclic monoterpenes are unstable in the gas-phase, which may contribute to difficulties calibrating instruments to gas-phase standards of these compounds, and could have implications for measurements of their emission rates. However, Raffa and Steffeck ran liquid injections, which suggests there may also be some issue with the FID response of acyclic monoterpenes. Linalool was also difficult to quantify. It has a molecular structure similar to myrcene with the addition of water to one of the double bonds forming an alcohol. This similarity in structure could suggest that linalool is also unstable in the gas phase, which would explain the observed results. However, it is also possible that the ECN contribution from a tertiary alcohol is actually lower than the previously reported value that was used to calculate the theoretical response $(-0.25)$. The theoretical tertiary alcohol ECN correction applied in this study is based on a single compound (tert-butyl alcohol) reported by Sternberg et al. (1962). Using the average ECN contribution value reported by Jorgensen (1990) for alcohol $(\triangle \mathrm{ECN}=-0.64)$ would lower the $\triangle \mathrm{ECN}$ for linalool from 0.14 to 0.10 relative to the theoretical ECN. Using this alternate value, the other compounds from this experiment that contained tertiary alcohols, $\mathrm{MBO}$ and linalool oxide, would still have $\triangle \mathrm{ECN}$ of 0.09 and 0.08 , respectively, relative to the theoretical ECN. These results both fall within the uncertainty of this analytical method.

\section{Conclusions}

The quantification of trace organic compounds in environmental samples requires careful analytical procedures, but obtaining reliable standards is difficult because of their instability and high cost. In order to accurately analyze biogenic compounds, it is essential to develop robust techniques to produce quantitative in-house standards that can be calibrated relative to a more stable NIST-traceable standard. This study describes a novel dynamic dilution system for generating standard mixtures of trace VOCs, and uses that system to quantify the FID response to numerous biogenic compounds important in atmospheric chemical processes. The dynamic dilution system is simple in design and easy to operate. It was found to be an effective tool for characterizing system response to target analytes and should be a reasonable solution for many laboratories investigating similar compounds. With it, we have demonstrated that in most cases the ECN correction values used here suffice for quantification of terpenoid compounds within $10 \%$ uncertainty, similar to the observed variability in the dynamic dilution system used to generate test gases. Furthermore, quantifying the uncertainty associated with this analytical system greatly improves confidence in results.

Perhaps more importantly, the dynamic dilution system has proven to be highly valuable as a quality control tool for the VOC sampling and analytical systems in our laboratory. To ensure accurate quantification, it is important to build a calibration system that introduces both standards and samples to the analytical system as similarly as possible. This verifies that the integrity of the entire sample collection apparatus is accounted for. As discussed above, our original analysis protocol would have resulted in erroneously low results for sesquiterpenes in environmental samples since the cryotrapping system was not adsorbing them effectively. Based on the information derived using the dilution system, we have improved our methodology. These results reinforce the utility of the FID for the quantification of complex environmental samples where theoretical response factors can be estimated to perform quantitative analysis within $10 \%$ uncertainty. Despite the predictability of FID response, measurements should be approached with careful quality control checks. It is still necessary to run representative gas standards for each type of analyte to ensure the entire sampling and analytical system is producing expected results.

Acknowledgements. C. Faiola gratefully acknowledges the support of a National Science Foundation IGERT Fellowship from the Biosphere-Atmosphere Research and Training program at the 
University of Michigan. Additional financial support was provided by a US Department of Energy Early Career Research Program award (\# SC0003899). The authors also acknowledge the helpful advice provided by E. Allwine at WSU and P. Harley and J. Ortega at the National Center for Atmospheric Research. We thank the two anonymous reviewers for their helpful suggestions.

Edited by: D. Riemer

\section{References}

Apel, E. C., Calvert, J. G., Gilpin, T. M., Fehsenfeld, F. C., Parrish, D. D., and Lonneman, W. A.: The Nonmethane Hydrocarbon Intercomparison Experiment (NOMHICE): Task 3, J. Geophys. Res., 104, 26069-26086, doi:199910.1029/1999JD900793, 1999.

Atkinson, R. and Arey, J.: Atmospheric Chemistry of Biogenic Organic Compounds, Accounts Chem. Res., 31, 574-583, doi:10.1021/ar970143z, 1998.

Atkinson, R. and Arey, J.: Gas-phase tropospheric chemistry of biogenic volatile organic compounds: a review, Atmos. Environ., 37 (Supplement 2), 197-219, doi:10.1016/S1352-2310(03)00391-1, 2003.

Clementi, S., Savelli, G., and Vergoni, M.: Relative molar response of flame lonisation detector to some heteroaromatic compounds, Chromatographia, 5, 413-414, 1972.

Demarcke, M., Müller, J. F., Schoon, N., Van Langenhove, H., Dewulf, J., Joó, E., Steppe, K., Simpraga, M., Heinesch, B., Aubinet, M., and Amelynck, C.: History effect of light and temperature on monoterpenoid emissions from Fagus sylvatica L, Atmos. Environ., 44, 3261-3268, 2010.

Duhl, T. R., Helmig, D., and Guenther, A.: Sesquiterpene emissions from vegetation: a review, Biogeosciences, 5, 761-777, doi:10.5194/bg-5-761-2008, 2008.

Engelberth, J., Alborn, H. T., Schmelz, E. A., and Tumlinson, J. H.: Airborne signals prime plants against insect herbivore attack, Proc. Natl. Acad. Sci. USA, 101, 1781-1785, 2004.

Ettre, L. S.: Chapter XXI: Relative Molar Response of Hydrocarbons on the Ionization Detectors, in: Gas Chromatography: Third International Symposium Held Under the Auspices of the Analysis Instrumentation Division of the Instrument Society of America, edited by: Brenner, N., Callen, J. E., and Weiss, M. D., 307327, Academic Press, New York and London, 1962.

Fahlbusch, K., Hammerschmidt, F., Panten, J., Pickenhagen, W., Schatkowski, D., Bauer, K., Garbe, D., and Surburg, H.: Flavors and Fragrances, in Ullmann's Encyclopedia of Industrial Chemistry, Wiley-VCH Verlag GmbH \& Co. KGaA., 2003.

de Gouw, J. and Warneke, C.: Measurements of volatile organic compounds in the earth's atmosphere using proton-transferreaction mass spectrometry, Mass Spectrom. Rev., 26, 223-257, doi:10.1002/mas.20119, 2007.

Guenther, A. B.: Seasonal and spatial variations in natural volatile organic compound emissions, Ecol. Appl., 7, 34-45, 1997.

Guenther, A., Hewitt, C. N., Erickson, D., Fall, R., Geron, C., Graedel, T., Harley, P., Klinger, L., Lerdau, M., McKay, W. A., Pierce, T., Scholes, B., Steinbrecher, R., Tallamraju, R., Taylor, J., and Zimmerman, P: A global model of natural volatile organic compound emissions, J. Geophys. Res., 100, 8873-8892, 1995.
Guenther, A., Geron, C., Pierce, T., Lamb, B., Harley, P., and Fall, R.: Natural emissions of non-methane volatile organic compounds, carbon monoxide, and oxides of nitrogen from North America, Atmos. Environ., 34, 2205-2230, 2000.

Guenther, A., Karl, T., Harley, P., Wiedinmyer, C., Palmer, P. I., and Geron, C.: Estimates of global terrestrial isoprene emissions using MEGAN (Model of Emissions of Gases and Aerosols from Nature), Atmos. Chem. Phys., 6, 3181-3210, doi:10.5194/acp-63181-2006, 2006.

Holm, T.: Aspects of the mechanism of the flame ionization detector, J. Chromatogr. A, 842, 221-227, doi:10.1016/S00219673(98)00706-7, 1999.

Jobson, B. T. and McCoskey, J. K.: Sample drying to improve $\mathrm{HCHO}$ measurements by PTR-MS instruments: laboratory and field measurements, Atmos. Chem. Phys., 10, 1821-1835, doi:10.5194/acp-10-1821-2010, 2010.

Jorgensen, A. D., Picel, K. C., and Stamoudis, V. C.: Prediction of gas chromatography flame ionization detector response factors from molecular structures, Anal. Chem., 62, 683-689, doi:10.1021/ac00206a007, 1990.

Kállai, M. and Balla, J.: The effect of molecular structure upon the response of the flame ionization detector, Chromatographia, 56, 357-360, 2002.

Kállai, M., Veres, Z., and Balla, J.: Response of flame ionization detectors to different homologous series, Chromatographia, 54, 511-517, 2001.

Kállai, M., Mate, V., and Balla, J.: Effects of experimental conditions on the determination of the effective carbon number, Chromatographia, 57, 639-644, 2003.

Kesselmeier, J. and Staudt, M.: Biogenic volatile organic compounds (VOC): an overview on emission, physiology and ecology, Journal of Atmospheric Chemistry, 33(1), 23-88, 1999.

Komenda, M., Parusel, E., Wedel, A., and Koppmann, R.: Measurements of biogenic VOC emissions: sampling, analysis and calibration, Atmos. Environ., 35, 2069-2080, doi:10.1016/S13522310(00)00502-1, 2001.

Lamb, B., Guenther, A., Gay, D., and Westberg, H.: A national inventory of biogenic hydrocarbon emissions, Atmos. Environ., 21, 1695-1705, 1987.

Lerdau, M., Litvak, M., and Monson, R.: Plant chemical defense: monoterpenes and the growth-differentiation balance hypothesis, Trends Ecol. Evol., 9, 58-61, doi:10.1016/0169-5347(94)90269$0,1994$.

Lerdau, M., Litvak, M., Palmer, P., and Monson, R.: Controls over monoterpene emissions from boreal forest conifers, Tree Physiol., 17, 563-569, doi:10.1093/treephys/17.8-9.563, 1997.

Ortega, J., Helmig, D., Daly, R. W., Tanner, D. M., Guenther, A. B., and Herrick, J. D.: Approaches for quantifying reactive and low-volatility biogenic organic compound emissions by vegetation enclosure techniques - part B: applications, Chemosphere, 72, 365-380, doi:10.1016/j.chemosphere.2008.02.054, 2008.

Parrish, D. D.: Critical evaluation of US on-road vehicle emission inventories, Atmos. Environ., 40, 2288-2300, doi:10.1016/j.atmosenv.2005.11.033, 2006.

Peñuelas, J. and Staudt, M.: BVOCs and global change, Trends Plant Sci., 15, 133-144, 2010.

Perkins, G., Rouayheb, G. M., Lively, L. D., and Hamilton, W. C.: Chapter XIX: Response of the Gas Chromatographic Flame Ionization Detector to Different Functional Groups, in: Gas 
Chromatography: Third International Symposium Held Under the Auspices of the Analysis Instrumentation Division of the Instrument Society of America, edited by: Brenner, N., Callen, J. E., and Weiss, M. D., 269-285, Academic Press, New York and London, 1962.

Raffa, K. F. and Steffeck, R. J.: Computation of response factors for quantitative analysis of monoterpenes by gasliquid chromatography, J. Chem. Ecol., 14, 1385-1390, doi:10.1007/BF01020142, 1988.

Sakulyanontvittaya, T., Duhl, T., Wiedinmyer, C., Helmig, D., Matsunaga, S., Potosnak, M., Milford, J., and Guenther, A.: Monoterpene and sesquiterpene emission estimates for the United States, Environ. Sci. Technol., 42, 1623-1629, 2008.
Scanlon, J. T. and Willis, D. E.: Calculation of flame ionization detector relative response factors using the effective carbon number concept, J. Chromatogr. Sci., 23, 333-340, 1985.

Sternberg, J. C., Gallaway, W. S., and Jones, D. T. L.: Chapter XVIII: The Mechanism of Response of Flame Ionization Detectors, in: Gas Chromatography: Third International Symposium Held Under the Auspices of the Analysis Instrumentation Division of the Instrument Society of America, edited by: Brenner, N., Callen, J. E., and Weiss, M. D., 231-267, Academic Press, New York and London, 1962.

Tong, H. Y. and Karasek, F. W.: Flame ionization detector response factors for compound classes in quantitative analysis of complex organic mixtures, Anal. Chem., 56, 2124-2128, doi:10.1021/ac00276a033, 1984. 